\title{
Structural Dimensions and Functions of Structure Influencing Agribusiness Enterprises: Mechanistic Vs Organic Systems Approach.
}

\author{
Ogidi, Armstrong. E. ${ }^{1}$ and Adekitan, Rasheed ${ }^{2}$ \\ ${ }^{I}$ Department of Agribusiness, University of Agriculture, P.M.B. 2373, Makurdi, Nigeria. \\ ${ }^{2}$ Department of Business Administration, University of Agriculture, P.M.B. 2373, Makurdi, Nigeria.
}

\begin{abstract}
The main aim of the study is to evaluate the structural dimensions and functions of structure influencing agribusiness enterprises: mechanistic vs. organic systems approach. Systematic or quasi-random sampling was used. The sample size for this research was made up of twenty (26) small-to-medium scale agribusiness enterprises in Benue State, Nigeria, from a population of fifty two (52). One hundred and two (102) respondents were framed for this study. Preliminary analysis sub-divided agribusiness enterprises into mechanistic and organic enterprises. The mechanistic agribusiness enterprises had higher correlations in terms of written procedures, job descriptions, policy manuals and rules and regulations. Tasks performed by organic agribusiness enterprises are not fractionated and the levels of job qualification were not highly specialized compared to mechanistic enterprises. Respondents in mechanistic and overall agribusiness enterprises had a more dissatisfied feeling when decisions are made exclusively by top management. For organic agribusiness enterprises to be innovative, they must improve on their formalization of job descriptions, policy manuals and rules and regulations. To improve the image of employees and the organization, vertical differentiation and the number of supervisors in organic agribusiness enterprises must be increased and defined properly. Mechanistic agribusiness enterprises should allow decentralization so as to foster intrapreneurship.
\end{abstract}

Key words: Agribusiness, functions of structure, mechanistic, organic, structural dimensions, synergy

\section{Introduction}

Organizational structures occupy a very important place in the management of organizations. Without organizational structures, the organization may not be able to function and perform its goals very well. In a highly stable and predictable environment, where market and technological conditions among others remain largely unchanging over time, the mechanistic system will be practiced (Burns and Stalker 1961). This is because in such situations, it is possible to reutilize tasks and centralize directions, in order to maximize efficiency and achieve effectiveness of operations. An organization or management is supposed to be proactive in the face of turbulent environments; such organizations and management need to be rationale. Organizations can use different structural configurations and internal control systems to adapt to environmental uncertainty (Daft, 1986). The seminal studies of Burns and Stalker (1961) and Lawrence and Lorsch (1967) among others, seem to coalesce to the notion of organic versus mechanistic designs. The organic structures are usually seen as free flowing, democratic, low in formalization and higher in autonomy and individualism, are supportive of change and innovation (Ottih and Orupabo, 2002).

Many agribusiness enterprises have used organic strategies to reshape their structures and functions, which have greatly enhanced better performance over the years. An example is the development of the cereal conversion plant by Cadbury Nigeria PLC to replace imported barley with local cereal for its glucose and malt requirements (Alabi, 1991; Ottih and Orupabo, 2002); Nestle Foods Nigeria PLC's modern foods processing factory which is now fed with raw materials from its farms, and the two firms of Nigeria Breweries PLC and Guinness Nigeria PLC, which have converted their barley-based plants to accommodate local sorghum and maize (The Guardian, 1991; Ottih and Orupabo, 2002). Over the years, Olam Nigeria Ltd. had developed an effective retail sales and distribution structure, and executed a differentiated product development and marketing strategy in selected categories and markets; Olam's Senior Vice President and Head of Packaged Foods, M. Ramanarayanan said: "this acquisition is an attractive proposition for our packaged foods business to enter and scale up in another large and attractive packaged foods category" (Value Fronteira, 2012). NASCO Group Nigeria Ltd has strategized its operations over the years into four broad categories namely: manufacturing, marketing, services and trading to suit it vision - a world in which people live the quality life (World Investment News, 2000). 


\section{Objectives of the Study}

The main objective of the study is to evaluate the structural dimensions and functions of structure of agribusiness enterprises operating in Benue State, Nigeria: mechanistic vs. organic systems approach. Specifically, the study was carried out in order to:

(i). find out the formalization practices that enhances waste reduction of inputs,

(ii). examine the action of specialization features on authoritarianism,

(iii). ascertain if standardization is a tool for judicious use of resources,

(iv). explore the role centralization plays in enhancing routine technology, and finally

(v). ascertain if hierarchy of authority is a means for controlling employees.

\section{Research Hypothesis}

$\mathbf{H O}_{1}$ : There is no significant relationship between formalization and waste reduction.

$\mathbf{H O}_{2}$ : There is no significant relationship between specialization and authoritarianism

$\mathbf{H O}_{3}$ : There is no significant relationship between standardization and judicious use of resources.

$\mathbf{H O}_{4}$ : There is no significant relationship between centralization and routine technology.

$\mathbf{H O}_{5}$ : There is no significant relationship between hierarchy of authority and employee control orientation.

\section{A Brief Theoretical Review}

\section{Literature Review}

Burns and Stalker (1961) ascertained that mechanistic systems were characterized by centralization of authority and control, a high degree of task specialization and primarily vertical communication; organic systems on the other hand, are characterized by a higher degree of task interdependence, greater decentralization of control and authority, and horizontal communication. Strategy has for many years been known as a major influence on structuring; the landmark study by Chandler (1962) caused this recognition. Chandler (1962) studied about 100 of America's largest firms in the early 1960s. He traced the development of these firms from 1909 to 1959, compiling case histories of firms such as Dupont, General Motors, Standard Oil of New Jersey and Sears. He concluded from these data that changes in corporate strategy preceded and led to organizational restructuring. As Chandler puts it, "a new strategy required a new, or at least, refashioned structure strategy, inefficiency results". Through chandler's work, he has argued that organizations typically began with a single product line, which can be in manufacturing, sales or warehousing. This strategy is followed by a loose or simple structure. Decisions are centralized in a single manager, low complexity cause low formalization. As the firm grows, strategies are more ambitious and elaborate.

From a single product line, companies mature into full production of the single line to achieve high economies. This leads to the employment of a mature functional structure engendering differentiation into production, marketing, personnel and accounting department. From this position, companies expand activities within the same industry and domain, employing the vertical integration strategy for better interdependence and synergy. The functional structure can still be used provided more coordination mechanisms are employed. As the firm grows further, it diversifies into the production of other products and product lines which now demand a structural form that allows for specialized attention to each product line to achieve coordination across functions, client satisfaction, and adaptation to each product environment. The findings of Woodward (1965) showed that: the ratio of indirect labor also increased with technical complexity, she also noted that span of control, formalization, written communication and centralization are high for mass production technology, but low for others because others require skilled workers and verbal communication to adapt to changing conditions, thus mass production firms were termed mechanistic while others were referred to as organic in nature. Lawrence and Lorsch (1969) discovered that plastic firms were typically characterized by high technological innovation and high market demand; the container industry on the other hand concentrated on the quality of product/service, while the food companies were characterized by a moderate amount of instability in the environment.

\section{Conceptual Framework}

(i) Structural Dimensions: Structural dimensions refer to variables, which are often used to describe and differentiate organization structures (Ottih, 2006). Structural dimensions or characteristics are presented below (Daft, 1986; Ottih, 2006): (a). Formalization: This refers to the amount of written documentation. It comprises of written procedures, decision rules, job descriptions, policy manuals, and rules and regulations. (b). Specialization: This pertains to the extent to which organizational tasks are divided into minute tasks. (c). Standardization: This refers to the extent to which similar tasks are performed in a uniform manner across the firm. This simply means that the methods by which things are done are predetermined, and workers do not use their own initiative. (d). Centralization: This is the extent to which decisions are made exclusively by the top 
management. When work-related decisions are made at the activity centers, the organization is said to be decentralized.

(ii) Functions of Structure: According to Ottih (2006), there are some basic functions that organization structures are supposed to perform and these functions are expected to feature predominantly in the minds of designers as the basic objectives in the design effort. Some of these functions are (Ottih, 2006): (a). Coordination: This refers to the ability of management to direct employee work performance towards desired objectives. (b). Communication: Communication is the exchange of information among organizational participants and units; some structures restrict communication to the vertical type, some permit a free-flow of information. (c). Innovation and Adaptation: This pertains to the ability of the organization to perceive environmental changes and introduce internal changes to adapt to those in the environment. Some organizational structural forms are too internally focused to readily perceive environmental changes. (d). Efficiency: Efficiency can be described as the judicious use of resources. Maximum efficiency is attained when it becomes impossible to reshuffle resources without decreasing the total value of product of the production. Efficiency in resources is ensured through specialization of workers, standardization of tasks, formalization, and strong control orientation, among others. (e). Job Satisfaction: Not all organization forms are designed to achieve job satisfaction. Those that are authoritarian, control orientated, highly formalized and above all, use routine technology, are often found to generate worker alienation and poor job satisfaction.

\section{Sampling Framework}

\section{Materials And Methods}

Systematic or quasi-random sampling (probability sampling) was used. This sampling method involves the selection of the ith subject from serially listed population where $i$ is any number usually determined by dividing the population by the required sample size. The sample frame consisted of timber enterprises (7), bread bakeries (6), beverage producers (4) and rice millers (9). Thus, the sample size (n) for this research was made up of twenty (26) small-to-medium scale agribusiness enterprises from a population of fifty two (52) in Benue State. This list was adopted from the Federal Republic of Nigeria Industrial Directory (2010).

TABLE 1: Agribusiness Sectors and Questionnaire Distribution

\begin{tabular}{lll}
\hline S/N & Agribusiness sectors & Number of enterprises (n) \\
\hline 1. & Timber enterprises & 7 \\
2. & Bread bakeries & 6 \\
3. & Beverage producers & 4 \\
4. & Rice millers & 9 \\
& Total n & $\mathbf{2 6}$ \\
\hline S/N & Groups & Questionnaire distribution $(\mathbf{N})$ \\
\hline 1. & Directors & 26 \\
2. & Production managers & 12 \\
3. & Marketing managers & 12 \\
4. & Finance managers & 12 \\
5. & Human resource managers & 12 \\
6. & Assistants & 28 \\
& Total N & $\mathbf{1 0 2}$ \\
\hline
\end{tabular}

Source: Field survey, 2011

The respondents' sample frame was made up of Directors (26), production managers (12), marketing managers (12), finance managers (12), human resource managers (12) and assistants (28) to give rise to a total of one hundred and two (102) respondents for this study (see Table 1).

\section{Data Collection and Measurement of Variables}

The main instrument for data generation and analysis was structured research questionnaire. Interview method and observation were also used to generate relevant qualitative data which revealed more information to compliment the questionnaires. Effort was also made to minimize the problem of developing a weak research instrument. All items were measured using a three-point Likert-like scale (1=low, 2=medium and 3=high).

\section{Data Analysis}

The extrapolated data from questionnaires were analyzed using computer-based Statistical Package for Social Sciences (SPSS) version 16. Spearman's Rank Order Correlation was used to test if correlation exists between hypothetical variables and analysis of variance (ANOVA) was used to test the hypotheses of the study. 


\section{Findings And Discussion}

Preliminary analysis sub-divided agribusiness enterprises into two categories. Twelve enterprises (12) or forty-six percent (46\%) of the twenty-six (26) enterprises in the study practiced mechanistic management system while fourteen (14) or fifty-four percent (54\%) practiced organic systems of management (see Table 2).

TABLE 2: Structures Practiced by Agribusiness Enterprises

\begin{tabular}{|c|c|c|c|}
\hline & \multirow[t]{2}{*}{ Agribusiness sectors $(n=26)$} & \multicolumn{2}{|c|}{ Systems of management } \\
\hline & & Mechanistic & Organic \\
\hline 1. & Timber enterprises & $1(14)$ & $6(86)$ \\
\hline 2. & Bread bakeries & $5(83)$ & $1(17)$ \\
\hline 3. & Beverage producers & $4(100)$ & $0(0)$ \\
\hline 4. & Rice millers & $2(22)$ & $7(78)$ \\
\hline & Total & $12(46)$ & $14(54)$ \\
\hline
\end{tabular}

Note: values in parenthesis are in percentages, $\mathrm{n}=$ number of sampled enterprises

Source: Field survey, 2011

Spearman's Rank Order Correlation (Rho) between Structural Dimensions and Functions of Structure of Agribusiness Enterprises in Benue State, Nigeria.

\section{(i) Formalization Vs Co-ordination}

A considerable correlation was noticed between co-ordination and the following: written procedures (Rho $=0.572$ for mechanistic enterprises), job descriptions ( $R h o=0.537$ for mechanistic enterprises), written procedures ( $\mathrm{Rho}=0.514$ for overall enterprises), policy manuals ( $\mathrm{Rho}=0.502$ for mechanistic enterprises), job descriptions ( $\mathrm{Rho}=0.500$ for overall enterprises), written procedures and job descriptions ( $\mathrm{Rho}=0.474$ and 0.472 for organic enterprises), and policy manuals (Rho $=0.430$ for overall manuals). Weak relationships were observed between co-ordination and the following: policy manuals (Rho $=0.342$ for organic enterprises), rules and regulation $(\mathrm{Rho}=0.332$ for mechanistic enterprises), rules and regulation ( $\mathrm{Rho}=0.233$ for overall enterprises). A very weak relationship is shown to exist between co-ordination and rules and regulations $(0.177$ for organic enterprises). The reason for this might probably be due to failure of the organic agribusiness enterprises to properly implement and control rules and regulations. The mechanistic agribusiness enterprises had higher correlations in terms of written procedures, job descriptions, policy manuals and rules and regulations. This means that mechanistic agribusiness enterprises were more formalized and focused in achieving organizational objectives.

TABLE 3: Summary of Correlation Coefficient between Formalization and Co-ordination

\begin{tabular}{lllll}
\hline Formalization & \multicolumn{5}{c}{ Co-ordination } \\
& Mechanistic $(N=60)$ & Organic $(N=42)$ & Overall $(N=102)$ \\
\hline written procedures & $0.572^{* *}(0.000)$ & $0.474^{* *}(0.000)$ & $0.514^{* *}(0.000)$ \\
job descriptions & $0.537^{* *}(0.000)$ & $0.472^{* *}(0.000)$ & $0.500^{* *}(0.000)$ \\
Policy manuals & $0.502^{* *}(0.000)$ & $0.342^{*}$ & $(0.025)$ & $0.430^{* *}(0.000)$ \\
rules and regulations & $0.332^{*}(0.030)$ & 0.177 & $(0.179)$ & $0.233^{*}(0.018)$ \\
\hline
\end{tabular}

Note: ** Correlation is significant at the 0.01 level (2-tailed), * Correlation is significant at the 0.05 level (2tailed)

Instrument - SPSS Version 16

Source: Research

\section{(ii) Specialization Vs Efficiency}

Positive correlations were established between specialization and efficiency. Moderate relationships among mechanistic agribusiness enterprises were noticed between: minute tasks in the organization and efficiency $(\mathrm{Rho}=0.569)$ and level of job qualification and efficiency $(\mathrm{Rho}=0.530)$. Weak relationships were exhibited by overall agribusiness enterprises: level of job qualification and efficiency (Rho $=0.282)$; minute tasks in the organization and efficiency (Rho=0.212). A very weak correlation was established between efficiency and the following: minute tasks in the organization and efficiency ( $\mathrm{Rho}=0.040$ for organic enterprises); level of job qualification and efficiency ( $\mathrm{Rho}=0.065$ for organic enterprises). This weak relationship could be that, the tasks performed by organic agribusiness enterprises are not fractionated and the levels of job qualification are not highly specialized compared to mechanistic enterprises - this is a deviation, because, literature stipulates that jobs in organic systems require high specialization. 
TABLE 4: Summary of Correlation Coefficient between Formalization and Co-ordination Specialization Efficiency

\begin{tabular}{llll} 
& Mechanistic $(N=60)$ & Organic $(N=42)$ & Overall $(N=102)$ \\
\hline minute tasks in the organization & $0.569^{* *}(0.000)$ & $0.040(0.762)$ & $0.212^{*}(0.033)$ \\
level of job qualification & $0.530^{* *}(0.000)$ & $0.065(0.621)$ & $0.282^{* *}(0.040)$ \\
\hline
\end{tabular}
Note: ** Correlation is significant at the 0.01 level (2-tailed), * Correlation is significant at the 0.05 level (2tailed) Source: Research Instrument - SPSS Version 16

\section{(ii) Standardization Vs Innovation and Adaptation}

Innovation and adaptation was moderately affected by tasks performed in a uniform manner (Rho $=0.560$ for mechanistic enterprises) as regards standardization. Weak relationships were mostly established between innovation and adaptation and the following: operations that are predetermined ( $\mathrm{Rho}=0.355$ for organic enterprises, $\mathrm{Rho}=0.345$ for mechanistic enterprises and $\mathrm{Rho}=0.320$ for overall enterprises) and tasks performed in a uniform manner ( $\mathrm{Rho}=0.343$ for overall enterprises). A very weak relationship was found between tasks performed in a uniform manner and innovation and adaptation for organic enterprises. The lack of innovation and adaptation exhibited by organic agribusiness enterprises is as a failure of management to improve the quality of goods and services. As customers continue to demand more quality standards in the external environment of business, the organic enterprises have failed to employ boundary spanners. Boundary spanners could have monitored technological changes that would have standardized tasks perfumed in a uniform manner and produced quality goods and services.

TABLE 5: Summary of Correlation Coefficient between Formalization and Co-ordination

\begin{tabular}{lllllll}
\hline Standardization & & \multicolumn{3}{c}{ Innovation and Adaptation } \\
\cline { 3 - 6 } & & & Mechanistic $(N=60)$ & Organic $(N=42)$ & Overall $(N=102)$ \\
\hline $\begin{array}{l}\text { tasks performed in a } \\
\text { manner }\end{array}$ & & uniform & $0.562^{* *}(0.000)$ & $0.185(0.156)$ & $0.343^{* *}(0.000)$ \\
operations that are pre-determined & $0.345^{*}(0.025)$ & $0.355^{* *}(0.006)$ & $0.320^{* *}(0.001)$ \\
\hline
\end{tabular}

Note: ** Correlation is significant at the 0.01 level (2-tailed), * Correlation is significant at the 0.05 level (2tailed) Source: Research Instrument - SPSS Version 16

\section{(iii) Centralization Vs Job Dissatisfaction}

Job dissatisfaction has been shown to be moderately influenced by: decisions made exclusively by top management (Rho $=0.514$ for overall enterprises, $\mathrm{Rho}=0.501$ for mechanistic enterprise and $\mathrm{Rho}=0.474$ for organic enterprises). Weak relationships were observed between job dissatisfaction and the following: implementation of decisions by top management $(\mathrm{Rho}=0.367$ for mechanistic enterprises and $\mathrm{Rho}=0.233$ for overall enterprises). A weak correlation exists between implementation of decisions made by top management and job dissatisfaction (Rho $=0.168$ for organic enterprises). This result shows that respondents in mechanistic and overall agribusiness enterprises have a more dissatisfied feeling when decisions are made exclusively by top management. This shows that employees in mechanistic agribusiness enterprises dislike authoritarianism, control orientation by top management which generates worker alienation.

TABLE 6: Summary of Correlation Coefficient between Formalization and Co-ordination

\begin{tabular}{llll}
\hline Centralization & \multicolumn{3}{c}{ Job dissatisfaction } \\
\cline { 2 - 4 } & Mechanistic $(N=60)$ & Organic $(N=42)$ & Overail $(N=102)$ \\
\hline decisions made exclusively by top mgt & $0.501^{* *}(0.000)$ & $0.474^{* *}(0.000)$ & $0.514^{* *}(0.000)$ \\
Implementation of decisions made by top & $0.367^{*}(0.017)$ & $0.168^{*}(0.199)$ & $0.233^{*}(0.018)$
\end{tabular}

$\mathrm{mgt}$

Note: ** Correlation is significant at the 0.01 level (2-tailed), * Correlation is significant at the 0.05 level (2tailed) Source: Research Instrument - SPSS Version 16

(iv) Hierarchy of Authority Vs Organizational and Individual Identity

Organizational and individual identity was moderately correlated with: levels of vertical differentiation (Rho $=0.547$ for mechanistic enterprises), levels of supervision by supervisors (Rho $=0.521$ for mechanistic enterprises and $\mathrm{Rho}=0.443$ for overall enterprises). Weak relationships were observed between organizational and individual identity and the following: levels of supervision by supervisors (Rho $=0.371$ for organic enterprises) and levels of vertical differentiation (Rho $=0.369$ for overall enterprises and a very weak Rho $=$ 0.228 for organic enterprises). This weak correlation in the organic sector could be due to the fact that these agribusiness enterprises have failed to improve the image and identification of employees and organization by not increasing the level of vertical differentiation and the number of supervisors. 
TABLE 7: Summary of Correlation Coefficient Between Formalization and Co-ordination

\begin{tabular}{llll}
\hline Hierarchy of Authority & \multicolumn{1}{l}{ Organizational and Individual Identity } & \\
\hline & Mechanistic $(N=60)$ & Organic $(N=42)$ & Overall $(N=102)$ \\
\hline levels of vertical differentiation & $0.547^{* *}(0.000)$ & $0.228(0.080)$ & $0.369^{* *}(0.000)$ \\
levels of supervision by & $0.521^{* *}(0.000)$ & $0.371^{* *}(0.004)$ & $0.443^{* *}(0.000)$
\end{tabular}

supervisors

Note: ** Correlation is significant at the 0.01 level (2-tailed)

Source: Research Instrument - SPSS Version 16

\section{Test of Hypothesis}

Analyses of Variance (ANOVA) between exogenous and endogenous variables were analyzed. The summary table abbreviations for the ANOVA tests are as follows: Source = source of variation, BG $=$ source of variance between the mean, $\mathrm{WG}=$ source of variance within the mean, $\mathrm{SS}=$ sum of square, Df $=$ degree of freedom; $\mathrm{MS}=$ mean square, $\mathrm{F}=\mathrm{F}$-value.

\section{Hypothesis One}

Table 8 shows that the Mean Square between (5.645) divided by the Mean Square within (0.169), yielded $\mathrm{F}=33.308$. The $\mathrm{p}$-value associated with this $\mathrm{F}$-value is zero $(0.000)$. In this study, the ANOVA result revealed that there is a significant relationship between formalization and co-ordination among agribusiness enterprises in Benue State, Nigeria at $\mathrm{F}=33.308$, and 0.05 significant level. The null hypothesis $\left(\mathrm{H}_{1}\right)$ is therefore rejected and the alternative hypothesis $\left(\mathrm{H} 1_{1}\right)$ is acceptable.

TABLE 8: Summary Showing the Analysis of Variance Between Formalization and Coordination Across Agribusiness Enterprises in Benue State, Nigeria ( $N=102)$.

\begin{tabular}{lllllll}
\multicolumn{7}{c}{ Agribusiness Enterprises in Benue State, Nigeria (N=102). } \\
\hline Source & SS & Df & MS & F & Sig. & Decision \\
\hline BG & 22.580 & 4 & 5.645 & 33.308 & 0.000 & Reject H0 $_{1}$ \\
WG & 16.440 & 98 & 0.169 & & & \\
\cline { 2 - 6 } & Total & 39.020 & 102 & & & \\
Note:
\end{tabular}

\section{Hypothesis Two}

The Mean Square between (2.171) divided by the Mean Square within (0.374), yielded F=5.810. The p-value associated with this F-value is zero (0.000). In this study, the ANOVA result revealed that there is a significant relationship between specialization and efficiency among agribusiness enterprises in Benue State, Nigeria at $\mathrm{F}=5.810$, and 0.05 significant level. The null hypothesis $\left(\mathrm{H}_{2}\right)$ is therefore rejected and the alternative hypothesis $\left(\mathrm{H}_{2}\right)$ is acceptable.

TABLE 9: Summary Showing the Analysis of Variance Between Specialization Vs Efficiency Across Agribusiness Enterprises in Benue State, Nigeria ( $N=102)$.

\begin{tabular}{lllllll}
\hline Source & SS & Df & MS & F & Sig. & Decision \\
\hline BG & 4.343 & 2 & 2.171 & 5.810 & 0.000 & Reject $\mathrm{H}_{2}$ \\
WG & 37.001 & 100 & 0.374 & & & \\
\hline Total & 41.344 & 102 & & & & \\
\hline
\end{tabular}

Note: *significant $\mathrm{P}<0.05$,

Source: Research Instrument - SPSS Version 16

\section{Hypothesis Three}

The Mean Square between (5.299) divided by the Mean Square within (0.311), yielded F=17.064. The p-value associated with this F-value is zero (0.000). In this study, the ANOVA result revealed that there is a significant relationship between standardization and innovation and adaptation among agribusiness enterprises in Benue State, Nigeria at $\mathrm{F}=17.064$, and 0.05 significant level. The null hypothesis $\left(\mathrm{H}_{3}\right)$ is therefore rejected and the alternative hypothesis $\left(\mathrm{H}_{3}\right)$ is acceptable.

TABLE 10: Summary Showing the Analysis of Variance Between Standardization Vs Innovation and Adaptation Across Agribusiness Enterprises in Benue State, Nigeria (N=102).

\begin{tabular}{lllllll}
\hline Source & SS & Df & MS & F & Sig. & Decision \\
\hline BG & 10.598 & 2 & 5.299 & 17.064 & 0.000 & ${\text { Reject } \mathrm{H}_{3}}_{\text {WG }}^{30.745}$ \\
\hline Total & 41.343 & 100 & 0.311 & & & \\
\hline
\end{tabular}


Note: *significant $\mathrm{P}<0.05$

Source: Research Instrument - SPSS Version 16

\section{Hypothesis Four}

The Mean Square between (7.094) divided by the Mean Square within (0.251), yielded F=28.281. The p-value associated with this F-value is zero (0.000). In this study, the ANOVA result revealed that there is a significant relationship between centralization and job dissatisfaction among agribusiness enterprises in Benue State, Nigeria at $\mathrm{F}=28.281$, and 0.05 significant level. The null hypothesis $\left(\mathrm{HO}_{4}\right)$ is therefore rejected and the alternative hypothesis $\left(\mathrm{H}_{4}\right)$ is acceptable.

TABLE 11: Summary Showing the Analysis of Variance Between Centralization Vs Job Dissatisfaction Across Agribusiness Enterprises in Benue State, Nigeria (N=102).

\begin{tabular}{lllllll}
\hline Source & SS & Df & MS & F & Sig. & Decision \\
\hline BG & 14.187 & 2 & 7.094 & 28.281 & 0.000 & Reject $\mathrm{H}_{4}$ \\
WG & 24.833 & 100 & 0.251 & & & \\
\hline Total & 39.020 & 102 & & & & \\
\hline
\end{tabular}

Note: *significant $\mathrm{P}<0.05$

Source: Research Instrument - SPSS Version 16

\section{Hypothesis Five}

The Mean Square between (4.910) divided by the Mean Square within (0.295), yielded $F=16.646$. The p-value associated with this F-value is zero (0.000). In this study, the ANOVA result revealed that there is a significant relationship between hierarchy of authority and organizational and individual identify among agribusiness enterprises in Benue State, Nigeria at $\mathrm{F}=16.646$, and 0.05 significant level. The null hypothesis $\left(\mathrm{HO}_{5}\right)$ is therefore rejected and the alternative hypothesis $\left(\mathrm{H}_{5}\right)$ is acceptable.

TABLE 12: Summary Showing the Analysis of Variance Between Hierarchy of Authority Vs Organizational and Individual Identity Across Agribusiness Enterprises in Benue State, Nigeria (N=102).

\begin{tabular}{lllllll}
\hline Source & SS & Df & MS & F & Sig. & Decision \\
\hline BG & 9.820 & 2 & 4.910 & 16.646 & 0.000 & Reject $\mathrm{H}_{5}$ \\
WG & 29.200 & 100 & 0.295 & & & \\
\hline Total & 39.020 & 102 & & & &
\end{tabular}

Note: *significant $\mathrm{P}<0.05$

Source: Research Instrument - SPSS Version 16

\section{Conclusion And Recommendations}

Preliminary analysis sub-divided agribusiness enterprises into two categories - mechanistic and organic. From the forgoing findings, the study concludes as follows:

(i) The mechanistic agribusiness enterprises had higher correlations in terms of written procedures,job descriptions, policy manuals and rules and regulations. This means that mechanistic agribusiness enterprises were more formalized and focused in achieving organizational objectives.

(ii) The tasks performed by organic agribusiness enterprises are not fractionated and the levelsofjob qualification is not highly specialized compared to mechanistic enterprises.

(iii) As customers continue to demand more quality standards from the external environment of business, the organic enterprises have failed to employ boundary spanners.

(iv) Respondents in mechanistic and overall agribusiness enterprises have a more dissatisfied feeling when decisions are made exclusively by top management. This shows that mechanistic employees dislike authoritarianism, control orientation by top management which generates worker alienation.

(v) The organic enterprises have failed to improve the image and identification of employees and organization by not increasing the level of vertical differentiation and the number of supervisors.

From our conclusion, the following recommendations are imperative:

(i) for organic agribusiness enterprises to be innovative and function properly, they must improve on their formalization of job descriptions, policy manuals and rules and regulations, expand activities within the same industry and domain, employ the vertical integration strategy for better interdependence and synergy,

(ii) tasks performed by both agribusiness enterprises should be fractionated into minute tasks so as to improve on job specialization in organic agribusiness enterprises,

(iii) boundary spanners should be installed and functional departments put in place to monitor technological changes that would standardize tasks performed in a uniform manner in organic agribusiness enterprises, 
(iv) mechanistic agribusiness enterprises should allow decentralization so as to foster for intrapreneurship, and finally

(v) improve the image and identification of employees and organization in organic agribusiness enterprises by increasing the level of vertical differentiation and the number of supervisors in the agribusiness enterprises.

\section{References}

[1] Alibi, M. (1991). Industrial Capacity Utilization Dips in First Half. Financial Guardian, Monday, Nov. $4: 15$.

[2] Burns, T. and Stalker, G.M. (1961). The Management of Innovation. London: Tavistock.

[3] Chandler, A. (1962). Strategy and Structure: Chapters in the History of the American Industrial Enterprise. Cambridge M.A: MIT Press. p. 21

[4] Daft, R.L. (1986). Organizational Theory and Design. St. Paul, MN: West Publishing Company. pp. 15-18.

[5] Ellis, F. (1988). Peasant economics: farm households and agrarian development. (2 ${ }^{\text {nd }}$ ed.). Cambridge: Cambridge University Press.

[6] Federal Republic of Nigeria Industrial Directory (2010)

[7] Hensher, M. (2001). Financing health systems through efficiency gains. CMH working paper series. Paper no. WG3: 2.

[8] Lawrence, P.R. and Lorsch, J.W. (1969). Organization and Environment. Homewood, I.L. Irwin.

[9] Olayide, S.O. and Heady, E.O. (1982). Introduction to agricultural production. Ibadan: Ibadan University Press. 319 pp.

[10] Ottih, L.O. (2006). Organization theory: Structure, design and process. Port Harcourt, Nigeria:Amex Publications. 119 pp

[11] Ottih, L.O. and Orupabo, T.J. (2002). The functional structure and corporate innovation. Nigerian Business and Social Review, 1(1): 91-106

[12] The Guardian (1991). Focus on Local Sourcing of Industrial Raw Materials: Prospects and Challenges of Looking Inwards. Author, October 5: 7 .

[13] Value Fronteira (2012). Singapore's Olam Buy’s Nigeria Biscuits Maker for $\$ 167$ Million.Accessed on the $13^{\text {th }}$ of August, 2012 from www.valuefronteira.com

[14] Woodward, J. (1965). Industrial Organizations: Theory and Practice. London: Oxford University Press.

[15] World Investment News (2000). The Quality life - The NASCO Vision: Forbes Global 12 $2^{\text {th }}$ June, 2000. Accessed on the $13^{\text {th }}$ of August, 2012 from www.winne.com 